\title{
Scavenging of ultrafine particles by rainfall at a boreal site: observations and model estimations
}

\author{
C. Andronache ${ }^{1}$, T. Grönholm ${ }^{2}$, L. Laakso ${ }^{2}$, V. Phillips ${ }^{3}$, and A. Venäläinen ${ }^{4}$ \\ ${ }^{1}$ Boston College, Chestnut Hill, Massachusetts, 02467 USA \\ ${ }^{2}$ Department of Physical Sciences, University of Helsinki, P.O. Box 64, 00014 Helsinki, Finland \\ ${ }^{3}$ Princeton University, Atmospheric and Oceanic Sciences Program, Princeton, New Jersey 08540, USA \\ ${ }^{4}$ Climate and Global Change Finnish Meteorological Institute Erik Palménin aukio 1, P.O. Box 503, 00101 Helsinki, Finland
}

Received: 16 December 2005 - Published in Atmos. Chem. Phys. Discuss.: 12 May 2006

Revised: 17 August 2006 - Accepted: 16 October 2006 - Published: 23 October 2006

\begin{abstract}
Values of the scavenging coefficient determined from observations of ultrafine particles (with diameters in the range $10-510 \mathrm{~nm}$ ) during rain events at a boreal forest site in Southern Finland between 1996 and 2001 were reported by Laakso et al. (2003a). The estimated range of the median values of the scavenging coefficient was $\left[7 \times 10^{-6}-4 \times 10^{-5}\right] \mathrm{s}^{-1}$, which is generally higher than model calculations based only on below-cloud processes (Brownian diffusion, interception, and typical phoretic and charge effects).

In the present study, in order to interpret these observed data on scavenging coefficients from Laakso et al. (2003a), we use a model that includes below-cloud scavenging processes, mixing of ultrafine particles from the boundary layer (BL) into cloud, followed by cloud condensation nuclei activation and in-cloud removal by rainfall. The range of effective scavenging coefficient predicted by the new model, corresponding to wide ranges of values of its input parameters, are compared with observations. Results show that ultrafine particle removal by rain depends on aerosol size, rainfall intensity, mixing processes between BL and cloud elements, in-cloud scavenged fraction, in-cloud collection efficiency, and in-cloud coagulation with cloud droplets.

The scavenging coefficients predicted by the new model are found to be significantly sensitive to the choice of representation of: (1) mixing processes; (2) raindrop size distribution; (3) phoretic effects in aerosol-raindrop collisions; and (4) cloud droplet activation. Implications for future studies of BL ultrafine particles scavenging are discussed.
\end{abstract}

Correspondence to: C. Andronache

(andronac@bc.edu)

\section{Introduction}

Aerosol particles are generated in the atmospheric environment by homogeneous nucleation of gaseous species, and by ion-induced nucleation (Covert et al., 1992; Widensohler et al., 1996; Raes et al., 1997; Weber et al., 1998; Kulmala et al., 1998, 2000a, 2004; Allen et al., 1999; O'Dowd et al., 1999; Birmili and Widensohler, 2000; Yu and Turco, 2001). Also, nucleation mode particles are emitted from gasoline engines (Harris and Maricq, 2001). Aitken mode particles are emitted directly from traffic exhaust, or may result from condensational growth of nucleation mode particles (Kerminen and Wexler, 1996; Alam et al., 2003: Laakso et al., 2003b). Accumulation mode particles originate from industrial combustion and re-suspension from road beds. Some aerosols originate from sea spray and cloud processing of particles and vapours. A significant source of aerosol particles is biomass burning (Andreae and Merlet, 2001). Particles larger than $100 \mathrm{~nm}$ are mainly mechanically generated: dust, re-suspension, industrial processes and sea-salt.

Ultrafine particles (UFP) are generally defined as aerosols with diameter $d_{p}<100 \mathrm{~nm}$. In this work, we will use UFP to describe the full range of available aerosol size [10-510] nm from the analyzed measurements (Laakso et al., 2003a). Homogeneous nucleation and direct injection of UFP into the atmospheric environment both act to increase particle concentrations. This affects visibility, cloud-condensation nuclei (CCN), and human health. After their formation, the fate of UFP is controlled by a combination of processes: advection, turbulent mixing, coagulation, condensation-evaporation, chemical reactions, aerosol-cloud interactions, and deposition (Seinfeld and Pandis, 1998; Jacobson, 2002). The sizes of UFP are augmented by the processes of condensation and coagulation, while their number concentration is reduced by coagulation with pre-existing aerosol particles and by various

Published by Copernicus GmbH on behalf of the European Geosciences Union. 


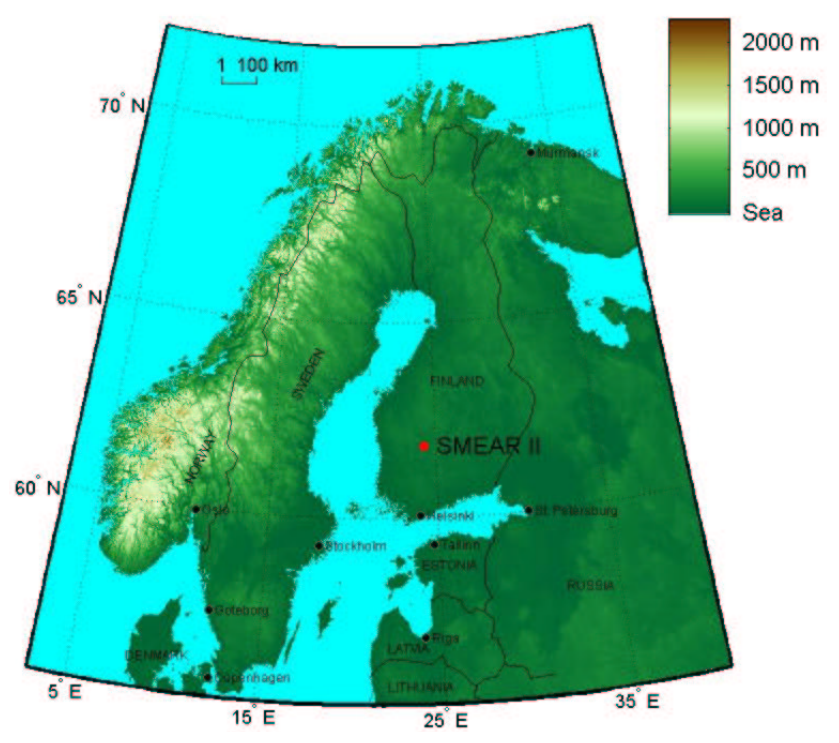

Fig. 1. Regional map with position of the observation site, SMEAR II in Southern Finland.

deposition processes. Kulmala et al. (2000a) showed that UFP with diameters, $d_{p} \sim 1-10 \mathrm{~nm}$, are efficiently scavenged by Brownian coagulation with larger ambient aerosols. The growth of UFP to sizes, $d_{p} \sim 10 \mathrm{~nm}$, is critical for the survival of such particles and for their potential influence on $\mathrm{CCN}$ concentrations. To become activated as cloud droplets, UFP need sufficient time to grow by condensation and coagulation. Rain is an effective mechanism for aerosol removal from the atmosphere and it can limit the number of small aerosol particles growing to the sizes required for activation of cloud droplets. Atmospheric particle removal is also a process of interest for numerical studies, in the effort to improve aerosol and chemical models at various scales (for example, see Rasch et al., 2000; Tost et al., 2006).

The wet removal of aerosol particles (AP) from atmosphere is caused by two processes: (a) if an AP is in the BL below-cloud, it can be collected by a falling raindrop ("below-cloud scavenging", BCS); (b) if an AP is in-cloud or at cloud base, where supersaturated conditions exist, it can become a cloud droplet by the nucleation scavenging process (Komppula et al., 2005). Such a particle grows to the size of a cloud droplet and can be efficiently collected by raindrops falling inside cloud ("in-cloud scavenging", ICS). In-cloud interstitial aerosol can be also be scavenged by coagulation with cloud droplets and by collection onto falling raindrops.

The below-cloud scavenging rate depends on the collection efficiency between a falling raindrop and aerosol particles. Throughout this paper we assume that the collection efficiency is equal to the collision efficiency. This assumption is correct if every collision between a UFP and a raindrop is followed by coalescence. It has been shown (Pruppacher and Klett, 1998) that a collision is followed by coalescence when $d_{p} / D_{p} \ll 1$, where $D_{p}$ is the raindrop diameter. This is because, in that case, the kinetic energy of tiny aerosol particles is relatively small in comparison with that of large particles (falling raindrops), causing the probability of bounce-off in collisions between small UFP and raindrops to be low. In that sense, the coalescence efficiency of UFP colliding with raindrops must be close to unity. The condition for coalescence during a collision is satisfied by typical UFP present in the BL below-cloud, where aerosol particles uptake water and become wet. These UFP behave as small spherical particles colliding with a falling raindrop.

Brownian diffusion is an efficient mechanism for collection of very small particles (with diameters $d_{p} \leq 10 \mathrm{~nm}$ ) by falling raindrops (Greenfield, 1957). Similarly, large particles (with diameters $d_{p} \geq 2000 \mathrm{~nm}$ ) have a relatively high collection efficiency because of their inertia, while particles with diameters in the range $10 \mathrm{~nm} \leq d_{p} \leq 2000 \mathrm{~nm}$ ("Greenfield gap"), tend to have small collection efficiencies. Slinn and Hales (1971) showed that thermophoresis could enhance the below-cloud scavenging of aerosols with diameters in the range [10-1000] nm. Work by Grover et al. (1977), Wang et al. (1978), McGann and Jennings (1991), Byrne and Jennings (1993), Tinsley et al. (2000), showed that presence of electric charge on aerosol particles and raindrops increases the below-cloud scavenging of aerosols with sizes in the "Greenfield gap".

A series of studies estimated the effects of below-cloud scavenging on aerosol size distribution under various environmental conditions (Dana and Hales, 1976; Wang and Pruppacher, 1977; Slinn, 1983; Ten Brink et al., 1987; Jylhä, 1991; Sparmacher et al., 1993; Andronache, 2003). Several reports estimated aerosol scavenging coefficients from direct measurements of the AP size distribution change at ground stations during rain events (Davenport and Peters, 1978; Schumann 1991; Laakso et al., 2003a; Chate and Pranesha, 2004; Maria and Russell, 2005). Scavenging rates determined from such measurements show a large spread, and tend to be significantly higher than estimations based only on below-cloud collection removal, accounting for Brownian diffusion, interception, and typical phoretic effects (Laakso et al., 2003a). Such results suggest that other processes are important in determining the overall observed scavenging of UFP from the BL. To address this problem, the present study has the following goal: to describe a modeling framework that accounts for below-cloud scavenging, UFP mixing into the cloud domain, nucleation scavenging and in-cloud scavenging. Such framework allows estimating the role of various processes in determining the aerosol scavenging as observed near ground, and is not intended as a new module for air pollution or aerosol transport models, which have transport and mixing processes explicitly represented. The model is used to evaluate the UFP effective scavenging coefficient, investigate its dependence on environmental parameters, and compare with observations. Possible implications for future field studies of aerosol scavenging are also discussed. 

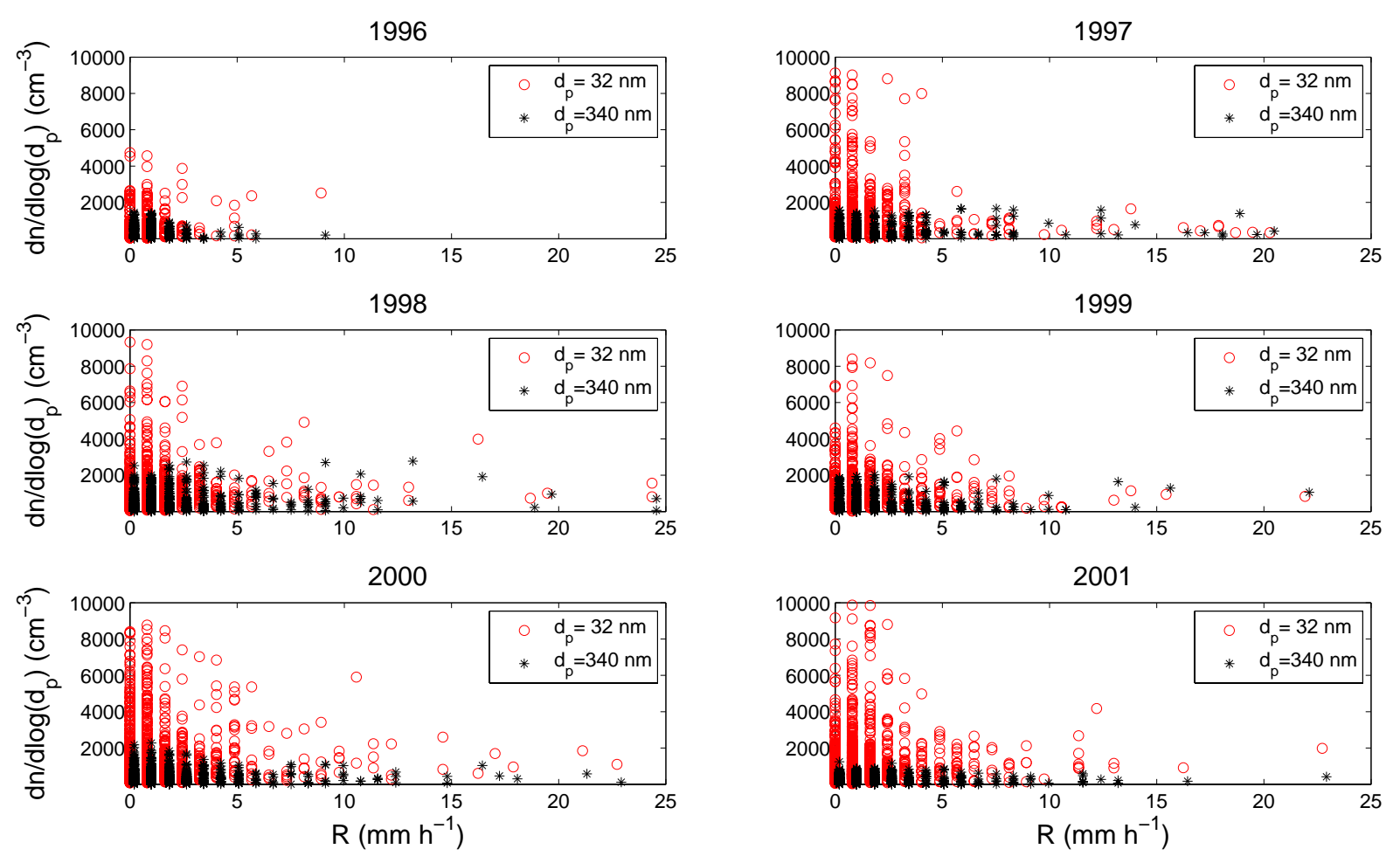

Fig. 2. Scatterplot of the measured $d n / d\left[\log \left(d_{p}\right)\right]$ (for two values of UFP diameter) versus rainfall rate $R$ during years $1996-2001$.

\section{Observations}

To determine the rate of scavenging of UFP during rain events, Laakso et al. (2003a) used data from six years (19962001) measurements at SMEAR II Station (Station for Measuring Forest Ecosystem-Atmosphere Relations), Hyytiälä, Southern Finland $\left(61^{\circ} 51^{\prime} \mathrm{N}, 24^{\circ} 17^{\prime} \mathrm{E} ; 181 \mathrm{~m}\right.$ a.s.l.) (Vesala et al., 1998; Mäkelä et al., 2000; Hyvönen et al., 2005) (Fig. 1). The station is located in a homogeneous Scots pine forest and is characterized by typical background conditions, with no local sources of pollution (Kulmala et al., 2000b). The particle size distributions between 3 and $510 \mathrm{~nm}$ have been measured by two differential mobility particle sizers (DMPS) for each $10 \mathrm{~min}$ period (Aalto et al., 2001). In their analysis, Laakso et al. (2003a) used data from the period between 1 May and 31 October of each year from 1996 to 2001, selecting rain events that lasted at least $0.5 \mathrm{~h}$ with a rain intensity $R \geq 0.4 \mathrm{~mm} \mathrm{~h}^{-1}$. Their analysis was also limited to particles with $d_{p} \geq 10 \mathrm{~nm}$, and a series of criteria were applied for data selection to minimize effects, on the UFP size distribution during rain events, arising from particle nucleation, growth by condensation and coagulation, dry deposition, and transport. Their experimental details will not be repeated here. In this section, considerations of UFP variability during rain events are presented, and the characteristics of precipitation in the region of interest are discussed.
A scatterplot of $d n / d \log \left(d_{p}\right)$ (for two particle diameters: $32 \mathrm{~nm}$ and $340 \mathrm{~nm}$ ) versus rainfall rate is shown in Fig. 2 for years 1996-2001. First, we note a substantial decrease of number concentration at any of the two selected diameters with the increase in rain intensity (The same result is seen at all UFP diameters). Second, the plot shows the predominance of cases with small rainfall rates $\sim 1 \mathrm{~mm} \mathrm{~h}^{-1}$. The number of samples with $R \geq 10 \mathrm{~mm} \mathrm{~h}^{-1}$ is almost negligible. During each rain event that has been analyzed, the measured size distribution of UFP changes in time. If wet removal were the only process acting on the aerosol population, we would see a decrease in aerosol concentration with time, over the duration of the rain event. Often, other processes alter the size distribution, and measurements show cases in which aerosol concentration can grow during precipitation. Such effects may be attributed to processes such as advection, mixing, and growth. An example of a change in the UFP size distribution with time is shown in Fig. 3 for a case observed on 9 October 1999. The rain event lasted $3 \mathrm{~h}$, with $R \sim 1 \mathrm{~mm} \mathrm{~h}^{-1}$, an air temperature between $6-9^{\circ} \mathrm{C}$, and a horizontal wind speed $\sim 1 \mathrm{~ms}^{-1}$. A continuous decrease of the number concentration over most of the range of particle diameter in the size distribution is seen, except for $d_{p} \leq 30 \mathrm{~nm}$ where there is a modest increase in number concentration. Such increases can be caused by transport, condensational growth and coagulation. This example illustrates the complexity of aerosol change during a relatively extended rain event. 

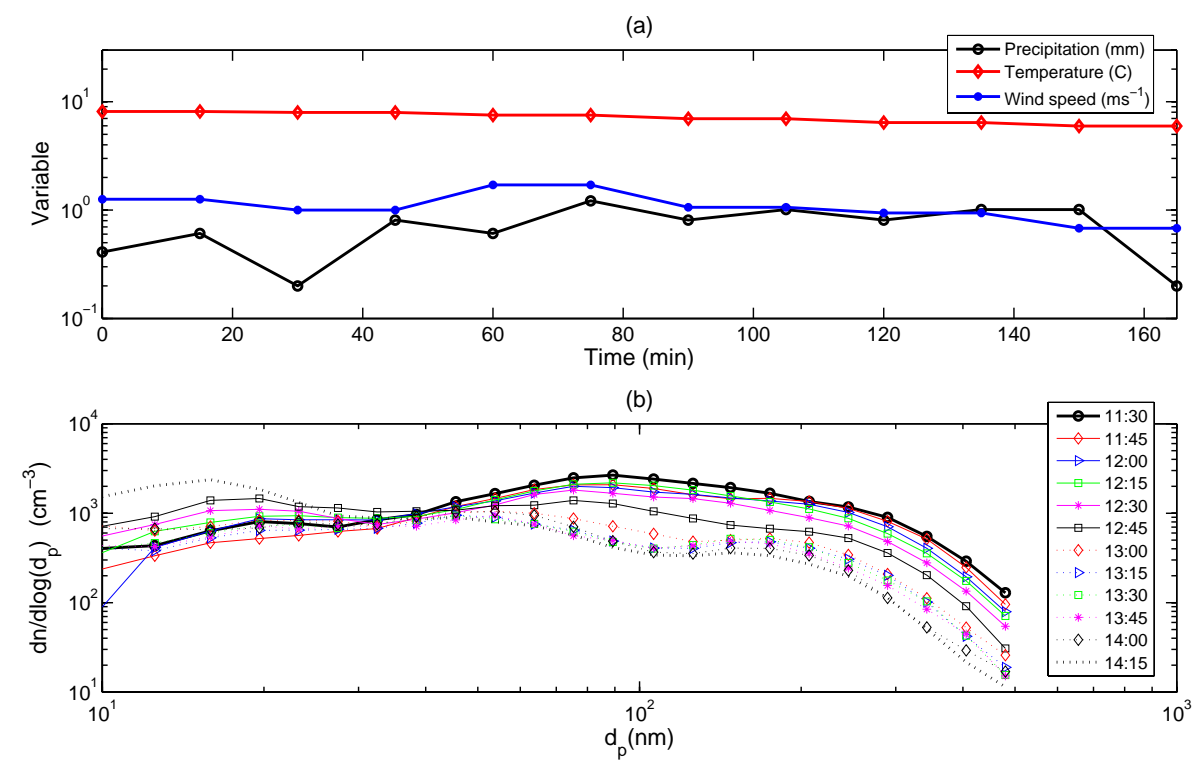

Fig. 3. (a) Observed meteorological parameters at $8.4 \mathrm{~m}$ above ground, and (b) aerosol size distribution versus local time during a precipitation event on 9 October 1999.

Analysis of meteorological data at Hyytiälä at $8.4 \mathrm{~m}$ above ground is illustrated in Fig. 4. Air temperature varied between 0 and $25^{\circ} \mathrm{C}$, and the accumulated precipitation recorded during $15 \mathrm{~min}$ is mostly less than $1 \mathrm{~mm}$, while the highest values reach $\sim 5 \mathrm{~mm}$ during the warmest months of the summer when convective precipitation is more frequent. However, such convective precipitation events are not too intense overall, since most cases produced $R \sim 1 \mathrm{~mm} \mathrm{~h}^{-1}$ (Fig. 4a). Rain duration (Fig. 4b) shows that the most frequent duration is less than $30 \mathrm{~min}$, and there are very few cases with continuous rain events lasting more than $2-3 \mathrm{~h}$. Figure $4 \mathrm{c}$ shows the distribution of horizontal wind intensity at $8.4 \mathrm{~m}$, with values being predominantly in the range of $0.5-2.5 \mathrm{~ms}^{-1}$. Figure $4 \mathrm{~d}$ shows the distribution of $\mathrm{RH}$ with values being mostly in the range of $90-100 \%$. There are a few cases of RH in the range of 60-90\% that are typically associated with the warmest periods and more intense precipitation events. Synoptic meteorological observations from Jokioinen $\left(60^{\circ} 49^{\prime} \mathrm{N}, 23^{\circ} 30^{\prime} \mathrm{E} ; 104 \mathrm{~m}\right.$ a.s.l.) provide details on cloud and precipitation types during rainy intervals recorded both at Jokioinen and Hyytiälä. The statistics of precipitation measured at the two stations is similar, which shows that the precipitation events at Hyytiälä and Jokioinen have similar properties. Data from Jokioinen show that precipitating clouds extended over all altitudes, and precipitation was classified into two types: frontal or shower precipitation. This is consistent with the overall picture of widespread stratiform precipitation being predominant, in conjunction with less frequent convective events.

The scavenging coefficient from observations, $L_{o}$ was estimated from measurements of UFP number concentration by
Laakso et al. (2003a) using:

$$
\frac{d n\left(d_{p}\right)}{d t}=-L_{o} n\left(d_{p}\right)
$$

where $n\left(d_{p}\right)$ is the UFP number concentration, and $d_{p}$ is the particle diameter. With $n\left(d_{p}\right)$ being measured at two times, $t_{1}$ and $t_{2}$, during rain events, the expression for $L_{o}$ becomes $L_{o}=-\frac{1}{\left(t_{2}-t_{1}\right)} \ln \left[\frac{n\left(t_{2}\right)}{n\left(t_{1}\right)}\right]$. The parameterization of $L_{o}$ is described in detail by Laakso et al. (2003a), being summarized in the Appendix. Thus, it has been determined that $L_{o}$ decreases with $d_{p}$ in the range $\sim 10-100 \mathrm{~nm}$, has a minimum for $d_{p}$ between 100-200 nm, and increases slightly for $d_{p}$ larger than $200 \mathrm{~nm}$. For any given aerosol diameter, $L_{o}$ increases with rain intensity as $\sqrt{R}$. Significant variability was observed from case to case, and results must be seen as representative for average conditions of widespread precipitation and rain duration consistent with the resolution of $R$ applied for the samples. These observed scavenging coefficients are compared with model results in the next section.

\section{Model description}

Modeling of the rate of UFP scavenging observed in the BL near the ground during rain events must consider these processes: (a) raindrops falling below-cloud collect UFP with an efficiency that depends on the sizes of aerosols and raindrops; (b) over the duration of a rain event, BL UFP are mixed throughout BL and within clouds. Some particles become cloud droplets or coagulate with cloud droplets and are removed while inside clouds. In-cloud entrainment is a complex dynamic process that occurs at the cloud base, lateral 

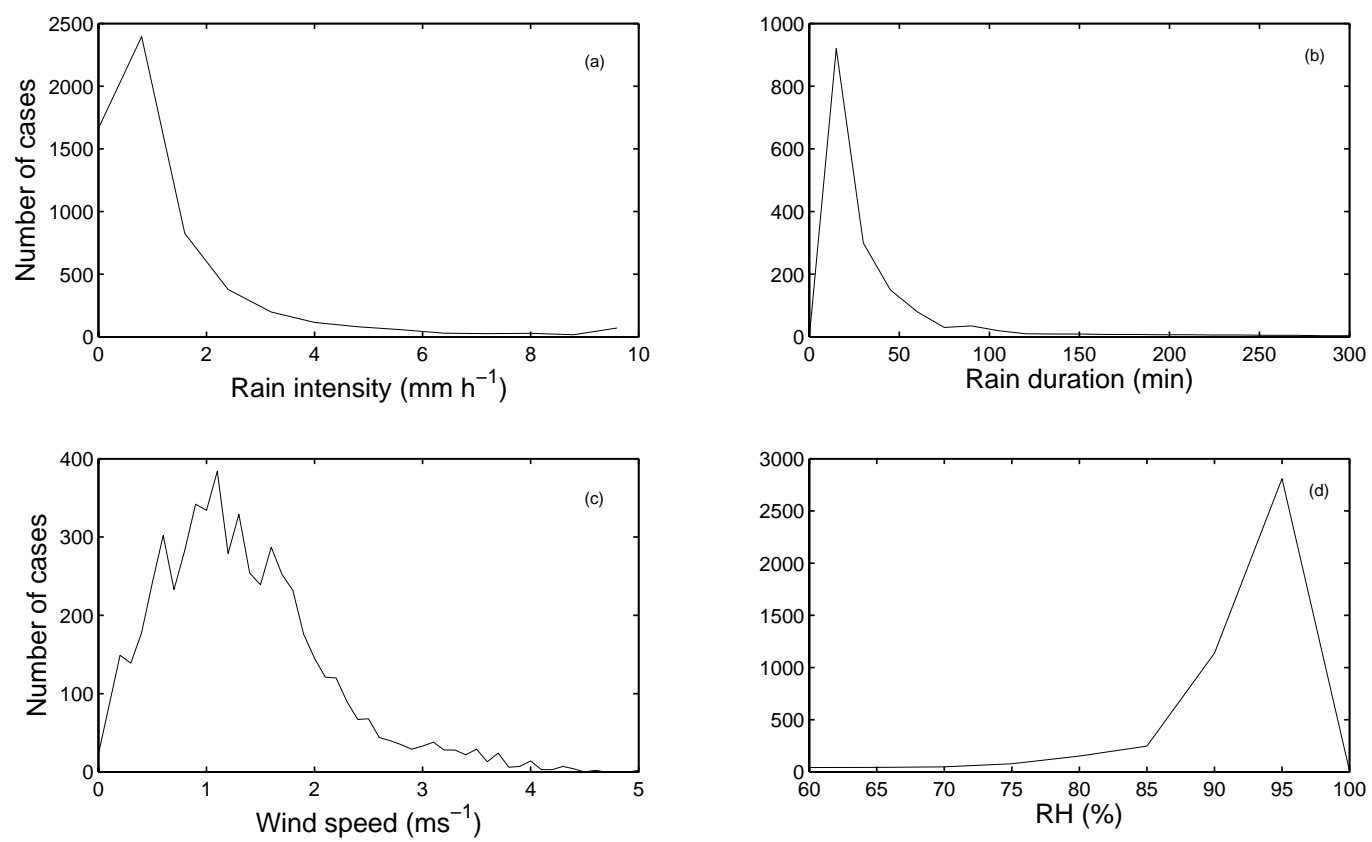

Fig. 4. Observed meteorological parameters at $8.4 \mathrm{~m}$ above ground at Hyytiälä recorded during precipitation events, for May-October interval, during years 1996-2001: (a) Frequency of rain intensity, $R$; (b) Frequency of rain duration; (c) Frequency of horizontal wind intensity; (d) Frequency of relative humidity, RH.

boundaries, and the top of the cloud. The focus of the present study is on entrainment at cloud base and lateral boundaries that results in mixing UFP from the BL into cloud elements. Although during precipitation such a process is highly inhomogeneous spatially and the entrainment rate varies with time, it will be characterised here by average values for a typical extent of a rain event. Insight into the physics of entrainment is available from direct field measurements (Martin et al., 1994; Svenningsson et al., 1997; Snider and Brenguier, 2000), lidar data, high-resolution dynamic models, including large eddy simulations, and mesoscale models applied for simulation of precipitation (Rutledge and Hobbs, 1983; Niewiadomski, 1986; Tremblay, 1987; Houze, 1993; Flossmann, 1998; Zhang et al., 2004; Agusti-Panareda et al., 2005). Such studies show significant variability of the parameters describing entrainment, and the important roles of turbulence and convection.

We are interested in the fraction, $f_{1}$, of BL UFP reaching cloud base or being mixed into cloud, and we adopt values reported in literature based on cloud modeling of tracer transfer between BL and free troposhere. Once UFP reach the cloud, where supersaturated conditions prevail, some particles become activated as cloud droplets by the nucleation scavenging process (e.g. Komppula et al., 2005). The scavenged fraction, $f_{2}$, depends on aerosol size, supersaturation and chemical composition, as will be discussed below. UFP, which are not affected by nucleation scavenging and are mixed into the cloud, are subject to coagulation with cloud droplets, which in turn have a high probability of being removed by raindrop collection.
With these considerations, the rate of change in the $\mathrm{BL}$ UFP due to precipitation is written as:

$\frac{d n\left(d_{p}\right)}{d t}=-L_{B C} n\left(d_{p}\right)+\left(\frac{d n\left(d_{p}\right)}{d t}\right)_{\text {mix }}$

where $n\left(d_{p}\right)$ is the BL UFP concentration, and $L_{B C}$ is the below-cloud scavenging coefficient. The first term on the right-hand side of the above equation represents the loss of BL UFP by falling raindrops below cloud. The second term on the right-hand side represents the loss of BL UFP by mixing into cloud by entrainment, followed by nucleation scavenging and in-cloud scavenging.

The second term of the right-hand side of Eq. (2) is expressed as:

$$
\left(\frac{d n\left(d_{p}\right)}{d t}\right)_{\text {mix }}=-f_{2} L_{I C}^{\text {coll }} f_{1} n\left(d_{p}\right)-L_{I C}^{\text {coag }} f_{1}\left(1-f_{2}\right) n\left(d_{p}\right)(3)
$$

where $f_{1}$ is the fraction of UFP from the BL that, by mixing and entrainment, reach cloud elements with supersaturated conditions. Also, $f_{2}$ is the fraction of such UFP that becomes activated as cloud droplets. $L_{I C}^{\text {coll }}$ is the in-cloud scavenging coefficient due to collection by raindrops inside cloud, and $L_{I C}^{\text {coag }}$ is the in-cloud scavenging coefficient due to UFP coagulation with cloud droplets.

Thus, Eq. (2) can be written as:

$\frac{d n\left(d_{p}\right)}{d t}=-L_{\mathrm{eff}} n\left(d_{p}\right)$

where $L_{\text {eff }}=L_{B C}+f_{1} f_{2} L_{I C}^{\text {coll }}+f_{1}\left(1-f_{2}\right) L_{I C}^{\text {coag }}$ is the effective (or apparent) scavenging coefficient of the BL UFP to be 
compared with $L_{o}$. Expressions for scavenging coefficients are given in Appendix A, and the list of notations is given in Appendix B.

\subsection{Mixing of ultrafine particles into cloud}

Entrainment of air and tracers into cloud depends on the intensity of vertical motions in the cloudy area, and has significant fluctuations over time and space. The nature of precipitation is also important, since stratiform clouds tend to produce a less intense mixing, and are limited in vertical extent, while deep convection is very efficient in rapid mixing of tracers throughout troposphere (Flossmann, 1998; Crutzen and Lawrence, 2000; Lawrence et al., 2003).

Stratiform and convective precipitation are classified as follows. Stratiform precipitation falls from nimbostratus clouds, while convective precipitation falls from cumulus and cumulonimbus clouds (Houze, 1993). Stratiform precipitation is a process in which vertical air motions are small compared with the fall velocity of ice crystals and snow $\left(\sim 1-3 \mathrm{~ms}^{-1}\right)$. The vertical velocity at cloud base for stratiform clouds is $w_{b} \sim 0.2-0.5 \mathrm{~ms}^{-1}$ based on detailed studies of frontal stratiform precipitation (Rutledge and Hobbs, 1983). Convective precipitation has a vertical velocity in the range $1-10 \mathrm{~ms}^{-1}$, which exceeds the typical fall speeds of snow and ice crystals.

For precipitation in Southern Finland that occurred during the sampling period, rain events are characterized by short durations ranging from less that $0.5 \mathrm{~h}$ to a few hours. Rainfall intensities were $R \sim 0.4-10 \mathrm{~mm} \mathrm{~h}^{-1}$, with values mostly being less than $1 \mathrm{~mm} \mathrm{~h}^{-1}$ (Fig. $4 \mathrm{a}$ ). Inspection of the precipitation data from Jokioinen shows that frontal systems moving from Atlantic region over the southern Finland during summer cover a large area dominated by low $R$. Embedded in the frontal systems are convective precipitation systems occupying a smaller area, where $R$ can be significantly higher. Often such frontal systems present a band structure that results in rain events interrupted by intervals of no rain or insignificant precipitation. Thus, for the time average of $R$ in this experiment (30 $\mathrm{min})$, the dominant precipitation is stratiform in nature, and strong convective cases are rare or are excluded from the analysis (Laakso et al., 2003a).

The value of $f_{1}$ utilized in the model is inferred from several previous studies of tracer transfer between the BL and the free troposphere, for conditions of interest in the present work. Firstly, with a three-dimensional cloud model, Niewiadomski (1986) studied the transfer of tracers from BL into free troposphere. The simulations represented many clouds in various stages of development. Niewiadomski showed that in $1 \mathrm{~h}$ the average BL tracer was reduced by $15 \%$. A value of $f_{1} \sim 0.15$ in 1 hour is inferred for UFP to reach the cloud base by vertical mixing. Secondly, Tremblay (1987) studied the role of cumulus cloud transport of chemical tracers, obtaining similar results to those of Niewiadomski. Both the measurements and the simulations with the three-dimensional model resulted in the net vertical transport rates of a few percent per hour. Thirdly, using the Met Office Unified Model to study ventilation of the BL, AgustiPanareda et al. (2005) recently determined the fraction of tracer transfer between BL and free troposphere for conditions of frontal cyclones over Europe. The fraction of the tracer in the BL transferred into the free troposphere was found to depend on convective conditions and tracer lifetime. For a tracer with lifetime of $3 \mathrm{~h}$, the transfer was about $f_{1} \sim 0.05 \mathrm{~h}^{-1}$ while significant variability has been attributed to the BL diurnal cycle. Because the frontal system did not cover all of the model domain in their study, their value of $f_{1}$ is expected to be lower than in cases where clouds cover the entire domain, as in the present study and in the modeling work by Niewiadomski (1986). Clearly, variability in convective conditions, duration of mixing, and the time scale of processes involved in tracer transformation, can all cause significant variations of the net fraction of BL tracer transferred into the free troposphere.

\subsection{In-cloud nucleation scavenging}

When aerosol particles reach the cloud base by mixing and are entrained into the cloud element, they encounter supersaturated conditions. A fraction, $f_{2}$, of such particles is then activated and form cloud droplets. Now, $f_{2}$ is often named the scavenged fraction or scavenged ratio (Svenningsson et al., 1997; Martinsson et al., 1999, Komppula et al., 2005). This is the process by which cloud droplets form on preexisting aerosol particles. Under subsaturated conditions, aerosol particles have equilibrium sizes determined by the ambient relative humidity $(\mathrm{RH})$ and the amount of soluble matter in the particle. At supersaturated conditions, particles can grow larger than the critical diameter and form cloud droplets. The supersaturation required for droplet activation depends mostly on the aerosol size and to some extent on the chemical composition of the aerosol particle. The supersaturation is governed by the rate of cooling of the air mass and the rate of condensation of vapour on the growing droplets. As a result, cloud formation causes a group of activated cloud droplets and another group of interstitial aerosol particles that both co-exist. The interstitial aerosol particles contain liquid or dry particles of equilibrium size (with diameters much smaller than cloud droplets). The study of aerosol hygroscopic behavior, aerosol activation, aerosol scavenged fraction, and cloud microphysics characteristics were extensively investigated in a series of field experiments and with numerical models (Martin et al., 1994; Garrett and Hobbs, 1995; Twohy et al., 1995; Svenningsson et al., 1997; Martinsson et al., 1999; Swietlicki et al., 1999; Komppula et al., 2005).

For a given local supersaturation $S$, the nucleation scavenging of AP is determined by the size and chemical composition of aerosols. Experimental determination of the scavenged fraction reveals the complexity of the nucleation scav- 
enging process, owing to variations in $S$ locally and in the chemical nature of AP (Martinsson et al., 1999; Komppula et al., 2005). Thus, for the same supersaturated conditions, some particles with diameters as low as $50 \mathrm{~nm}$ become activated, while a small fraction of particles with $d_{p} \geq 200 \mathrm{~nm}$ can remain unactivated. The scavenging fraction tends to increase rapidly with $d_{p}$ at diameters around $100 \mathrm{~nm}$. Model simulations of soluble aerosol, with an updraft velocity that produces local supersaturations of $\sim 0.1-0.2 \%$, predict a sharp increase of $f_{2}$ with particle diameter (Svenningsson et al., 1997). To account for possible variability in aerosol chemical composition and variations in $S$, we adopt an $f_{2}$ function (Fig. 5) that summarizes experimental results by Martinsson et al. (1999) and Komppula et al. (2005). The thick black curve represents the $f_{2}$-function used for the standard run to be compared with $L_{o}$. The blue lines show the range of $f_{2}$ data reported by Martinsson et al. (1999) are based on observations from air masses with predominantly continental influences, occasionally impacted by pollution, as reflected in the observed large number concentration of cloud droplets. The red dotted lines with symbols represent the range of $f_{2}$ based on data reported by Komppula et al. (2005) for the station Pallas in Northern Finland, a pristine continental site, often impacted by clean maritime air masses. Data from the two studies overlap for conditions specific to continental air masses, while the red curve with rhombic symbols from Komppula et al. (2005) is more representative for clean maritime air masses. We choose $f_{2}$ to approximate typical continental air masses because at Hyytiälä, the impact of continental influences is more significant than at Pallas.

\subsection{In-cloud collection and coagulation scavenging}

The UFP that undergo nucleation scavenging grow to cloud droplet size and are removed by falling raindrops inside clouds. This leads to a scavenging coefficient $L_{I C}^{\text {coll }}$ given in Appendix A. The physics of this process is the following: as UFP are drawn into the cloud, they are activated as CCN and grow to a cloud droplet size with a diameter $\sim 10 \mu \mathrm{m}$. The collection efficiency $E_{I C}$ for cloud droplets of $10 \mu \mathrm{m}$ in diameter varies between 0.5 and 0.8 when the collectors are raindrops with diameter $D_{p} \sim 0.2-2 \mathrm{~mm}$ (Slinn, 1977). These considerations apply also for highly soluble aerosol, or aerosol attached to material that is highly soluble, such that particles can grow to a droplet size. For aerosol that is less soluble, the collection efficiency can be lower than 0.5 . For snow, $E_{I C} \sim 0.1-0.3$, based on estimations by Scott (1982).

Another aspect of the in-cloud collection by rainfall is the vertical variation of rainfall intensity $R$. Measurements usually only yield $R$ values at the ground. Scott (1982) shows that for summer precipitations, $R$ measured at the ground is representative of the BL, while above the cloud base, $R$ decreases with height and becomes negligible at $z \sim 6-7 \mathrm{~km}$.

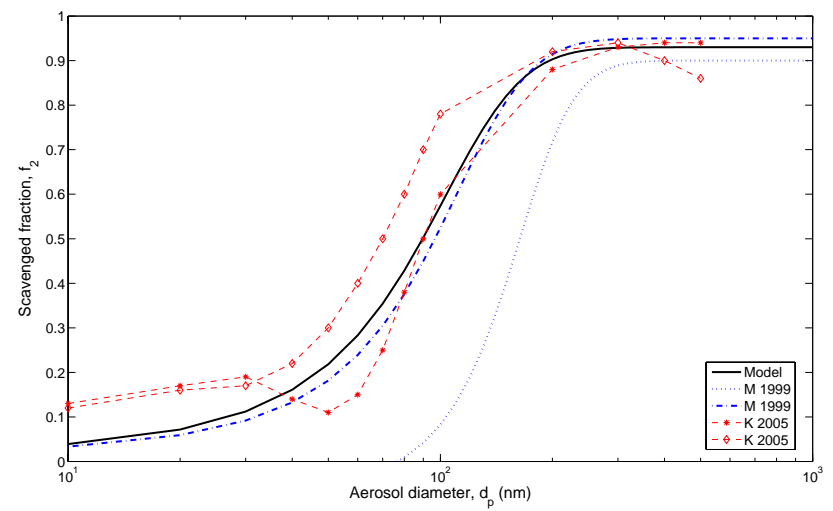

Fig. 5. Scavenged fraction $f_{2}$ of UFP mixed into cloud. The black curve is the function used in the model runs shown in results, while the dotted curves represent the boundaries which contain the scavenged fraction determined from observations by Martinsson et al. (1999) (M 1999) and Komppula et al. (2005) (K 2005).

Thus, we estimated that average in-cloud rainfall intensity, $R_{I C}$, is about half of the ground value, $R$.

The second important mechanism of in-cloud removal of UFP is for the small UFP that are not affected by nucleation scavenging (mostly with $d_{p} \leq 100 \mathrm{~nm}$ ). These particles can coagulate with cloud droplets, raindrops or remain as interstitial aerosol. It can be shown that UFP coagulation with raindrops is insignificant because the number concentration of raindrops is much lower than that of cloud droplets. UFP coagulation with cloud droplets is important, and can lead to inclusion of UFP into droplets, followed by raindrop collection. This process leads to a scavenging coefficient, $L_{I C}^{\mathrm{coag}}$, described in Appendix A. Next section describes comparisons between model calculations and observations, and illustrates model sensitivity to several important parameters.

\section{Results}

\subsection{Effective scavenging coefficient}

With the above considerations, a reference run to estimate the effective scavenging coefficient $L_{\text {eff }}$ was produced based on the following numerical values of various parameters: $R=1 \mathrm{~mm} \mathrm{~h}^{-1}, t_{c}=10^{\circ} \mathrm{C}, N_{0}=8 \times 10^{6} \mathrm{~m}^{-4}, E_{I C}=0.5, f_{1}=0.1$, $N_{c}=500 \mathrm{~cm}^{-3}, d_{c}=10 \mu \mathrm{m}, T_{a}-T_{s}=1^{\circ} \mathrm{C}$. Table 1 summarizes several model parameters, their values used in the reference run and the range of values used in sensitivity calculations. Estimated values of $L_{\text {eff }}$ from the model are shown in Fig. 6 for neutral and charged particles, at two values of the relative humidity, $\mathrm{RH}=60 \%$ and $\mathrm{RH}=95 \%$. Model predictions of $L_{\mathrm{eff}}$ are comparable with $L_{o}$ from observations within the uncertainties in several parameters used, as illustrated below by sensitivity simulations. The black dashed lines represent approximations of $L_{o}$ uncertainty from observations. The 
Table 1. Model parameters and their values used in the reference run and in sensitivity calculations.

\begin{tabular}{llll}
\hline Parameter & Reference run & Range & Notes \\
\hline$t_{c}$ & $10(\operatorname{deg} C)$ & $0-20(\operatorname{degC})$ & (a) \\
$\mathrm{RH}$ & $95 \%$ & $60-99 \%$ & $(\mathrm{~b})$ \\
$N_{0}$ & $8 \times 10^{6} \mathrm{~m}^{-4}$ & {$[4-16] \times 10^{6} \mathrm{~m}^{-4}$} & $(\mathrm{c})$ \\
$N_{c}$ & $500 \mathrm{~cm}^{-3}$ & $500-1500 \mathrm{~cm}^{-3}$ & $(\mathrm{~d})$ \\
$f_{1}$ & 0.1 & $0.05-0.15$ & $(\mathrm{e})$ \\
$E_{I C}$ & 0.5 & $0.1-0.9$ & $(\mathrm{f})$ \\
$T_{a}-T_{S}$ & $1(\operatorname{degC})$ & $0-5(\operatorname{degC})$ & $(\mathrm{g})$ \\
\hline
\end{tabular}

(a) Air temperature at $8.4 \mathrm{~m}$ above ground was in the range [0-20] $\operatorname{degC}$, with values mostly being $\sim 10 \operatorname{degC}$ (Laakso et al., 2003a); (b) Most samples have relative humidity $\mathrm{RH} \geq 60 \%$ with predominant values $\mathrm{RH} \geq 90 \%$; (c) $N_{0}$, the intercept parameter in the Marshall and Palmer raindrop size distribution can vary significantly; (d) Number concentration of cloud droplets was varied between clean continental to polluted conditions; (e) Fraction of UFP mixed into cloud elements was varied between 0.05 and 0.15 ; (f) Incloud collection efficiency was varied between 0.1 (for less soluble aerosols) and 0.9 (highly soluble aerosols); (g) The temperature difference between air and raindrop surface $\left(T_{a}-T_{S}\right)$ was varied between 0 ( $\operatorname{deg} C$ ) (in which case, thermophoresis is neglected) and 5 $(\operatorname{degC})$ (case with significant phoretic effects).

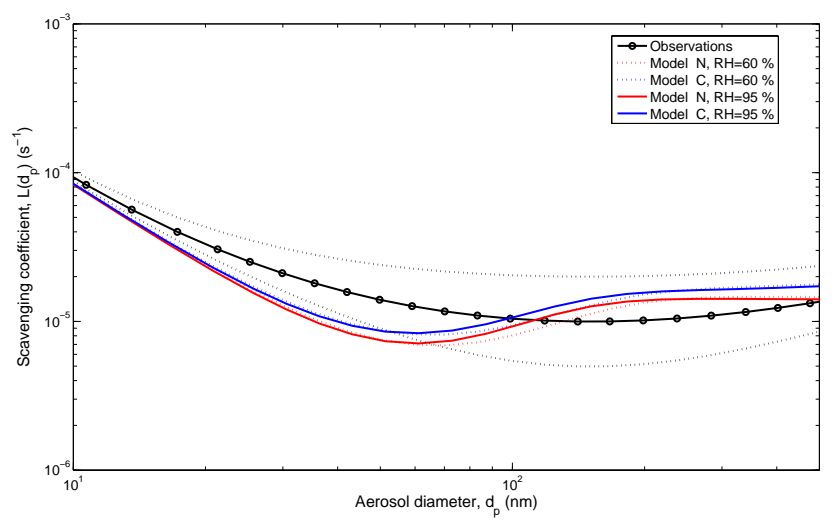

Fig. 6. Scavenging coefficient versus UFP diameter. Shown are $L_{o}$ from observations, and $L_{\text {eff }}$ model calculated for neutral $(\mathrm{N})$ and charged (C) particles, for two relative humidity values, $\mathrm{RH}=60 \%$ and $\mathrm{RH}=95 \%$. The two black dashed lines represent the uncertainties of the scavenging coefficient from observations.

calculated $L_{\text {eff }}$ tends has a minimum value for UFP diameter less than $100 \mathrm{~nm}$. The position of this minimum varies with model parameters such as $f_{2}$, and the overall shape of $L_{\mathrm{eff}}$ depends on phoretic effects and in-cloud removal rate as will become evident in the sensitivity calculations below.

The role of electric charge does not seem significant, and it is reasonable to assume that this mechanism is not important for predominantly stratiform precipitation based on reported data (Pruppacher and Klett, 1998). The Coulomb interaction

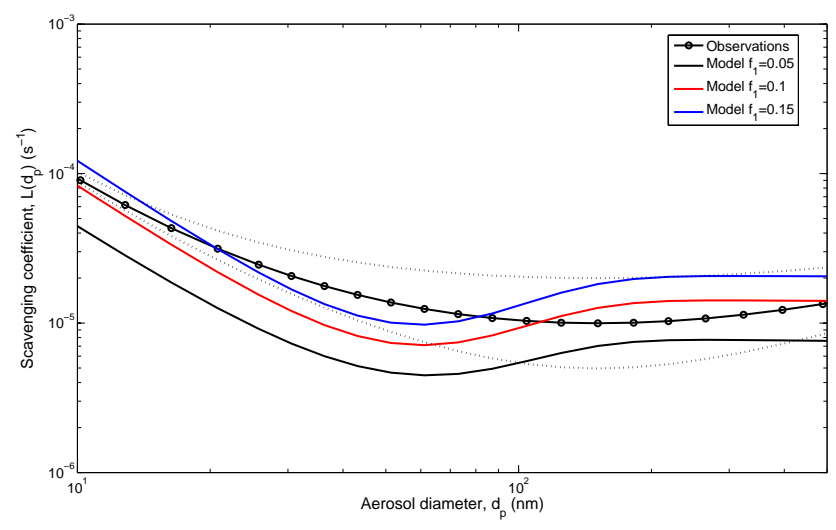

Fig. 7. Sensitivity of model results to the fraction of UFP mixed into cloud, $f_{1}$. The two black dashed lines represent the uncertainties of the scavenging coefficient from observations.

for average charge is important for thunderstorms and highly electrified clouds, becoming more evident at high values of $R$ (associated with convective precipitation). The possible effect of image charges can be important as well but it is not included in this model. The presence of ions at SMEAR II (Laakso et al., 2004), and work by Tinsley et al. (2000), Tripathi and Harrison (2001), Harrison and Carslaw (2003) indicate that electrostatic charge image interaction is possible between AP and raindrops. There is not yet a direct experimental account of the role of electric charge in UFP scavenging, and in the rest of the paper we will show results only for neutral particles.

The effect of the growth factor (GF) of UFP is important for determining which particles become activated by nucleation scavenging. GF has less effect on very small particles that coagulate with cloud droplets because GF is at most $\sim 2$ while between UFP diameters and cloud droplets there is a size difference of orders of magnitude. Thus coagulation between very small UFP and cloud droplets is not affected greatly by GF. Similarly, for UFP with $d_{p} \geq 100 \mathrm{~nm}$, in-cloud scavenging is less sensitive to further growth in diameter and we see less impact of GF on the overall scavenging of particles larger than $100 \mathrm{~nm}$. The highest effect of the growth factor is seen for $d_{p}$ in the range 50-100 $\mathrm{nm}$ where GF can make a significant difference. Thus, while a dry UFP of $d_{p}=50 \mathrm{~nm}$ has a small scavenged fraction, after the size change due to the GF, such particle becomes closer to $100 \mathrm{~nm}$ and can be scavenged more effectively.

The effect of air temperature on UFP scavenging is low for liquid precipitation. Caution is needed when using the model for cases when $t_{c}$ near the ground is close to $0^{\circ} \mathrm{C}$. In such cases, it is possible that at higher altitudes, precipitation inside cloud is solid and the collection efficiency as well as the hydrometeor size distribution in cloud might be different. Based on criteria for data selection, the possible number of cases with low $t_{c}$ is small and the overall scavenging co- 


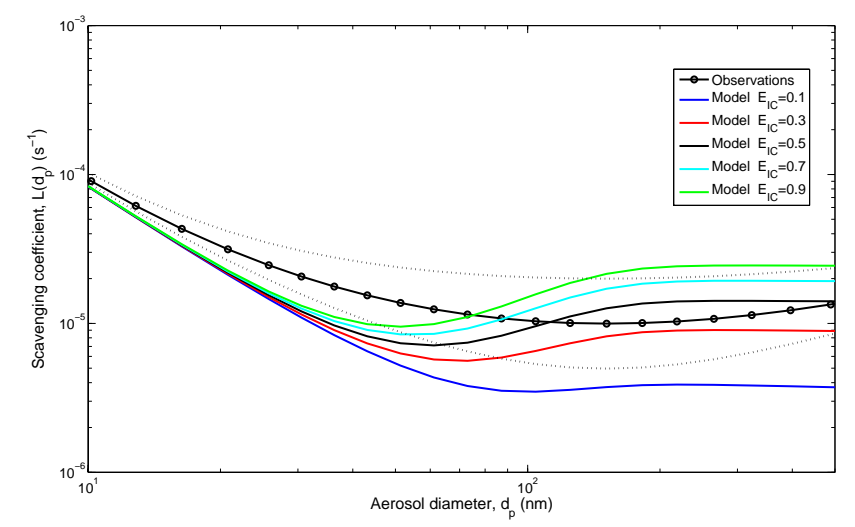

Fig. 8. Sensitivity of model results to in-cloud efficiency of collection $\left(E_{I C}\right)$ between cloud droplets and falling raindrops. The two black dashed lines represent the uncertainties of the scavenging coefficient from observations.

efficient is determined by scavenging onto liquid raindrops. The choice of value for $N_{0}$ is based on the standard Marshall and Palmer raindrop size distribution parameters (described in Appendix A), but we note possible large variations of this parameter and sensitivity of results will be shown below.

\subsection{Sensitivity calculations}

The model described above depends on several parameters that exhibit large variations during rain events. In order to illustrate possible variations in model results, we show sensitivity tests in which the parameter of interest is varied while the parameters have the values used in the reference run. Figure 7 shows the model sensitivity with respect to the fraction, $f_{1}$, of UFP from the BL that are mixed into cloud elements. The value of $f_{1}$ increases with average vertical velocity over the precipitation area, and is linked to a higher percentage of convective elements and to increased rainfall rates, $R$. The fraction $f_{1}$ is varied between 0.05 and 0.15 in this calculation, and other parameters are maintained at the constant values used for the simulations presented in Fig. 6. A larger increase of $f_{1}$ will require a higher value of $R$ because intense vertical transport is generally associated with convective precipitation. It is possible in principle to use a detailed mesoscale model and estimate $f_{1}$ over an area of interest, correlating it with the measured or estimated rainfall rate, $R$, at the ground. Since the mixing of UFP is practically independent of aerosol size, this parameter influences all aerosolcloud interactions described above (nucleation scavenging, in-cloud coagulation and collection). Thus, $L_{\text {eff }}$ values increase with $f_{1}$ for the the entire range of UFP diameters.

Figure 8 shows model $L_{\text {eff }}$ sensitivity to the in-cloud collection efficiency $E_{I C}$. This parameter is varied between 0.1 and 0.9. The case $E_{I C}=0.1$ illustrates the model result when in-cloud collection by raindrops is negligible. In this case, the model predicted $L_{\text {eff }}$ is significantlly smaller than $L_{o}$.

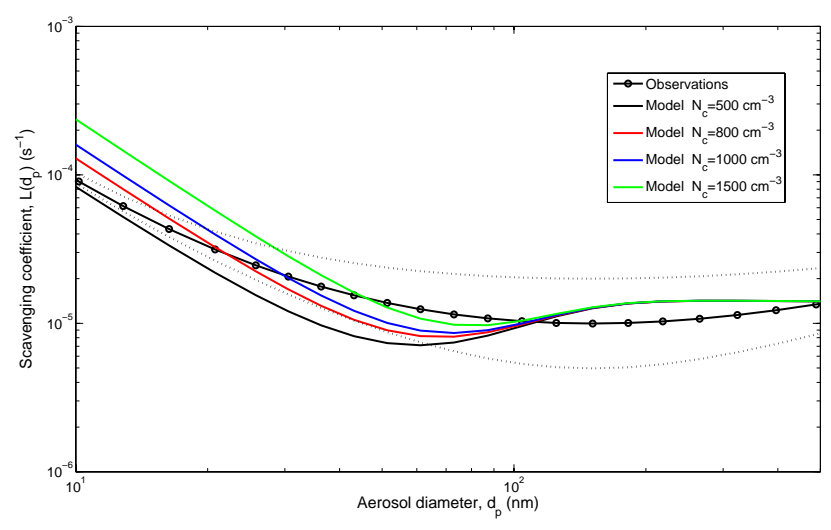

Fig. 9. Sensitivity of model results to cloud droplet number concentration, $N_{c}$. The two black dashed lines represent the uncertainties of the scavenging coefficient from observations.

$E_{I C}$ varies with chemical nature of aerosol and precipitation type. For liquid precipitation, small values of $E_{I C}(\sim 0.1-$ 0.3 ) are associated with less soluble aerosol, fresh soot or combustion aerosol. Such cases are related to air masses originating from the continent, perhaps passing over significant sources of combustion particles. Small $E_{I C}$ values are also associated with solid precipitation. The $E_{I C}$ values for snow are much smaller $(\sim 0.1-0.3)$ based on Scott (1982) and consistent with the results of Slinn (1977). Based on the temperature distribution near the ground for the samples used, the number of cases with possible snow precipitation in-cloud is quite limited and the overall influence on $L_{o}$ is low as well. Note the remarkable sensitivity of estimated values of $L_{\text {eff }}$ with respect to the in-cloud collection efficiency, especially for particles with $d_{p} \geq 50 \mathrm{~nm}$.

Figure 9 shows model sensitivity of $L_{\text {eff }}$ with respect to number concentration $N_{c}$ of cloud droplets. In the reference run we use $N_{c}=500 \mathrm{~cm}^{-3}$, which is quite typical for continental clouds. Possible influences from polluted air masses over Europe causes higher number concentrations of cloud droplets (and lower average diameters of cloud droplets). We varied $N_{c}$ between 500 and $1500 \mathrm{~cm}^{-3}$, which is consistent with data from field experiments that characterized cloud microphysics (Martinsson et al., 1999). For maritime stratiform clouds, $N_{c}$ is considerably lower, in the range $100-200 \mathrm{~cm}^{-3}$ (Martin et al., 1994). Overall, the increase of $N_{c}$ tends to increase UFP removal by coagulation, assuming the average diameter does not change considerably. In fact, the average diameter of cloud droplets changes with the number concentration of droplets: larger $N_{c}$ leads to smaller cloud droplets, which have slightly lower rates of coagulation with UFP. The sensitivity with respect to changes in cloud droplet diameter (not shown) indicates a similar range of variation of $L_{\mathrm{eff}}$.

Figure 10 shows model sensitivity temperature difference between air and raindrop surface, $\delta T=T_{a}-T_{S}$. For $\delta T=0^{\circ} \mathrm{C}$, there are no thermophoretic effects. The increase of $\delta T$ re- 


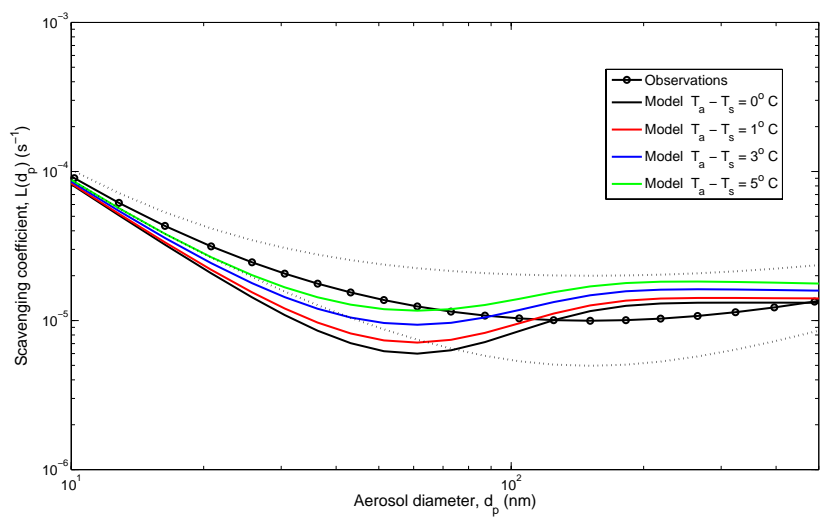

Fig. 10. Sensitivity of model results to temperature difference between ambient air and raindrop surface, $T_{a}-T_{s}$. The two black dashed lines represent the uncertainties of the scavenging coefficient from observations.

sults in significant enhancement of the scavenging coefficient especially for UFP diameters smaller than $100 \mathrm{~nm}$. The contribution of phoretic effects remains uncertain because of possible large fluctuations in $\delta T$ and relative humidity close to raindrop surface. In real rain events, a falling raindrop has a temperature different from the ambient air due to its origin at higher altitudes in cloud and due to raindrop surface cooling by evaporation. The rate of evaporation depends on the relative humidity near raidrop surface. From our analysis of RH values at Hyytiälä, some of the lowest values correspond to the warmest periods, when also more convective precipitation are possible. Low RH favors rapid evaporation of raindrops, which can lead to larger $\delta T=T_{a}-T_{s}$ and more intense phoretic effects.

Figure 11 illustrates model sensitivity of $L_{\text {eff }}$ with respect to $N_{0}$, the intercept parameter of the Marshall-Palmer size distribution of raindrops. The standard value for $N_{0}$ is considered representative and stable for long term averages of the widespread precipitation. Field data show that $N_{0}$ can vary significantly (Pruppacher and Klett, 1998), and we illustrate the impact on model results caused by variations of one order of magnitude. Generally, $L_{B C}$ is quite sensitive to $N_{0}$, which is reflected in the overall estimate of $L_{\text {eff }}$, especially for UFP with $d_{p} \leq 100 \mathrm{~nm}$. So far, results were presented using the Marshall and Palmer RSD. We note that MP RSD overestimates the number of very small and very large raindrops. Other RSD functions have been proposed to fit observations, and one common choice is Gamma function with three parameters: $N\left(D_{p}\right)=N_{o g} D_{p}^{\mu_{g}} \exp \left(-\Lambda_{g} D_{p}\right)$. For $\mu_{g}=0$ this RSD has the MP shape. Zhang et al. (2001) assumed a RSD as a Gamma function and they determined the three governing parameters from radar measurements: reflectivity, differential reflectivity and a constrained relation between the shape $\left(\mu_{g}\right)$ and slope $\left(\Lambda_{g}\right)$ parameters derived from disdrometer observations. RSD for $\mu_{g}=2,3,4$ are used here to calculate $L_{\text {eff }}$ and are compared in Fig. 12. Compar-

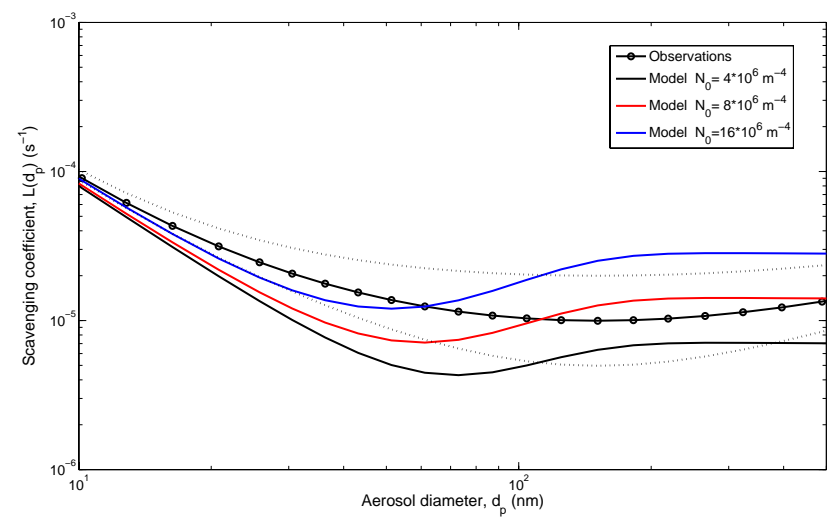

Fig. 11. Sensitivity of model results to Marshall and Palmer raindrop size distribution intercept parameter, $N_{0}$. The two black dashed lines represent the uncertainties of the scavenging coefficient from observations.

isons with calculations based on MP RSD shows that Gamma function gives larger model scavenging coefficients. This suggests that variations in the RSD function and its parameters is a source of significant uncertainty in calculated scavenging coefficients.

Finally, Fig. 13 illustrates the change in aerosol size distribution due to scavenging for two cases. Case 1 is based on $L_{\text {eff }}$ corresponding to parameters used in the reference run illustrated in Fig. 6. Case 2 is based on enhanched scavenging coefficient $L_{\text {eff }}$, determined for several parameter values selected from the upper range values used in sensitivity simulations. Thus, for Case $2, f_{1}=0.15, E_{I C}=0.8$, $N_{0}=16 \times 10^{6} \mathrm{~m}^{-4}$ and $T_{a}-T_{s}=5^{\circ} \mathrm{C}$, while the other parameters have values as those used in Case 1. The initial UFP size distribution is the median aerosol size distribution from all observations taken during rain events. For Case 1, we note that after $1 \mathrm{~h}$, there are notable changes, especially for particles with smaller diameters, and after $3 \mathrm{~h}$ the effect is enhanced. For Case 2, there is a major change overall suggesting that scavenging during $1-3 \mathrm{~h}$ can significantly reduce UFP number concentration for all sizes.

The model results shown above, indicate a range of calculated $L_{\text {eff }}$, quite sensitive to the assumed parameters. These values are comparable with the observed values $L_{o}$ for the UFP scavenging coefficient, within model parameters uncertainties and experimental errors. We must keep in mind the limitations of the modeling framework used here, including uncertainties in the vertical mixing, simplified treatment of cloud droplet activation, lack of detailed knowledge of raindrop size distribution, and parameters controlling phoretic and electric charge effects. It is interesting to note that other attempts to determine $L_{o}$ from ground measurements of changes in aerosol size distribution have been published. Table 2 shows $L_{o}$ reported from several field experiments in various places. Discrepancies between values in different experiments are about one order of magnitude and can 


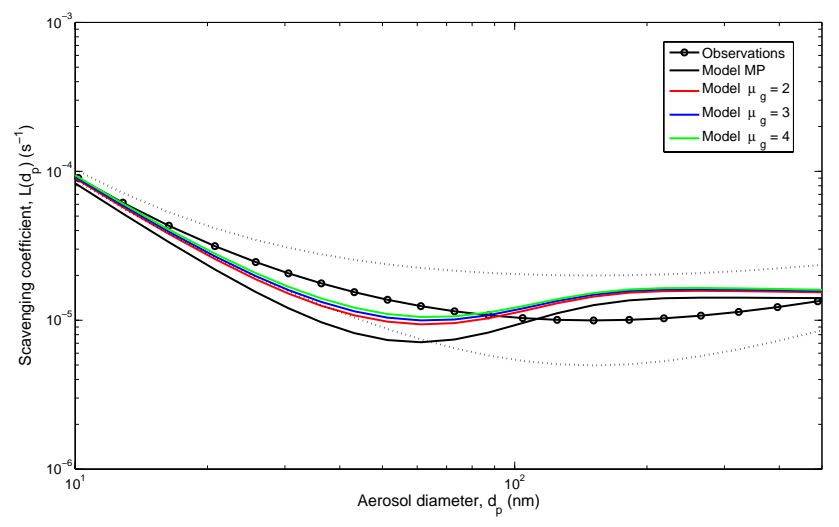

Fig. 12. Sensitivity of model results to raindrop size distribution function. Comparison of results for Marshall and Palmer RSD and a Gamma function RSD, for three values of the shape parameter $\left(\mu_{g}\right)$ based on data from Zhang et al. (2001). The two black dashed lines represent the uncertainties of the scavenging coefficient from observations.

be caused by the rainfall intensity range, precipitation type, different mixing conditions, variations in other environmental parameters and experimental errors. Future work will be needed to determine the role of each relevant factor and improve methodologies for scavenging coefficient determination using ground based measurements during rain events.

\section{Conclusions}

Scavenging coefficients with median values in the range $\left[7 \times 10^{-6}-4 \times 10^{-5}\right] \mathrm{s}^{-1}$, were reported by Laakso et al. (2003a) from six years of ultrafine particle (UFP) observations during rain events at a boreal forest site in Southern Finland. These values are comparable with results from similar experiments, for the same rainfall rates, but are generally higher than model calculations based only on belowcloud processes (Brownian diffusion, interception, and typical phoretic and charge effects).

In order to understand the possible role of various physical factors involved UFP scavenging during rain events, a model is presented, based on these processes: (1) UFP below-cloud scavenging by falling raindrops; (2) UFP mixing in-cloud and nucleation scavenging; and (3) UFP in-cloud collection and in-cloud coagulation with cloud droplets. Results from the model show overall reasonable agreement with observed values (within the range of experimental uncertainties). Nevertheless, significant sensitivity to parameters related to mixing and cloud microphysics is found in sensitivity tests.

These results are applicable to predominant stratiform precipitation that is not too intense $\left(R \sim 1 \mathrm{~mm} \mathrm{~h}^{-1}\right)$. Our results suggest that the net loss of UFP near the ground during a rain event is the outcome of below-cloud scavenging due to aerosol collection by raindrops, mixing, cloud droplet ac-

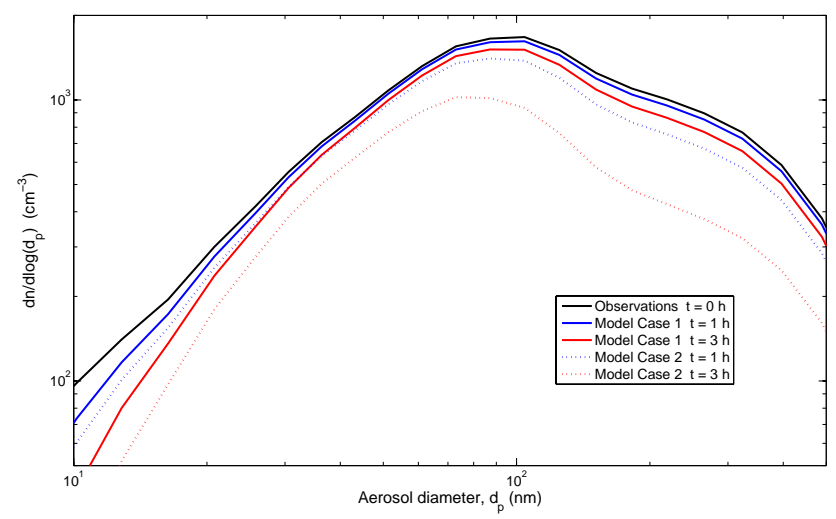

Fig. 13. Model calculated changes in the ultrafine particle size distribution. The initial size distribution is the median of all observations during rainy periods. Changes are shown after 1 and $3 \mathrm{~h}$, for two cases: Case 1 corresponds to $L_{\text {eff }}$ calculated with model parameters used in the reference run described in Fig. 6, and Case 2 corresponds to model parameters for more intense estimated $L_{\mathrm{eff}}$ $\left(f_{1}=0.15, E_{I C}=0.8, N_{0}=16 \times 10^{6} \mathrm{~m}^{-4}, T_{a}-T_{S}=5^{\circ} \mathrm{C}\right)$.

tivation and in-cloud scavenging. The importance of each process is determined by the mixing between BL and cloud elements. If rates of mixing are reduced, then the belowcloud scavenging caused by raindrop collection becomes important. However, for typical mixing during rain event, the in-cloud processes prevail, and can impact directly the overall UFP scavenging from the BL.

Simulations with the new model show that ultrafine particle removal from the BL by rain depends on aerosol size, rainfall intensity, mixing processes between $\mathrm{BL}$ and cloud elements, the in-cloud scavenged fraction, the in-cloud collection efficiency, and in-cloud coagulation with cloud droplets. The chemical composition and aerosol history of chemical processing can impact the growth factor, possibly affecting the scavenged fraction of those particles that reach supersaturation conditions. Other effects related to electric charge may affect also the overall scavenging by increasing the efficiency of collection. Their role needs to be further investigated by direct measurements and by refining of current models of scavenging.

Future work to improve characterization of the scavenging coefficients, and our ability to estimate the loss of BL aerosol by precipitation, needs to include measurements of properties of cloud hydrometeors, such as vertical profiles of rainfall, raindrop size distributions, and electric charge. It is particularly important to use more detailed models with explicit aerosol transport and microphysics to evaluate the role of various terms illustrated here. Mesoscale models can be used to infer rates of mixing between BL and cloud region and determine the role of vertical and horizontal mixing in UFP changes near ground. The work needs also to be extended for snowfall precipitation, which is relevant for wintertime geographic regions that can cover large areas, moun- 
Table 2. Range of reported aerosol scavenging coefficient determined from measurements of the size distribution during rain events.

\begin{tabular}{|c|c|c|c|}
\hline $\begin{array}{l}L_{o} \\
\left(s^{-1}\right)\end{array}$ & $\begin{array}{l}R \\
\left(\mathrm{~mm} \mathrm{~h}^{-1}\right)\end{array}$ & Location & Reference \\
\hline $2 \times 10^{-5}-1 \times 10^{-4}$ & $1-3$ & Lexington, Kentucky, USA & Davenport and Peters $(1978)^{\mathrm{a}}$ \\
\hline $7 \times 10^{-6}-4 \times 10^{-5}$ & $0.5-10$ & Hyytiälä, Finland & Laakso et al. $(2003 a)^{b}$ \\
\hline $1 \times 10^{-5}-8 \times 10^{-4}$ & $1-46$ & Pune, India & Chate and Pranesha $(2004)^{\mathrm{c}}$ \\
\hline $4 \times 10^{-5}-1 \times 10^{-4}$ & $1-20$ & Princeton, New Jersey, USA & Maria and Russell (2005) ${ }^{d}$ \\
\hline
\end{tabular}

\footnotetext{
a Experiments were conducted during three rain events on 1 September, 25 October and 30 October 1976. The rain events were widespread precipitation. Aerosol measurements were limited to two subranges of the size distribution: one with $d_{p}$ in the range [7-22] nm, and the other with $d_{p} \geq 400 \mathrm{~nm}$.

b Measurements were taken during May-October months, 1996-2001. Aerosol size distribution measured for $d_{p}$ in the range [3-510] nm. Rain events were characterized by predominant low intensities (see text for details).

${ }^{\mathrm{c}}$ Measurements were taken during a total of 17 rain events: two days in the pre-monsoon season in April 1997, and ten days post-monsoon during October and November 1997. Eight aerosol particle sizes with $d_{p}$ in the range [13-750] nm were used in the experiment. Precipitations were dominated by strong convective activity and thunderstorms.

d Observations were conducted during 10-day period in August 2003. Particle sizes measured ranged between $10 \mathrm{~nm}$ and $20000 \mathrm{~nm}$. Precipitation rate varied between 1 and $20 \mathrm{~mm} \mathrm{~h}^{-1}$.
}

tainous and high latitude regions. Such studies will be addressed during the International Polar Year 2007-2008.

\section{Appendix A}

\section{Scavenging coefficient}

The below-cloud scavenging coefficient $L_{B C}$ has expression

$L_{B C}\left(d_{p}\right)=\int_{0}^{\infty} \frac{\pi}{4} D_{p}^{2} U\left(D_{p}\right) E_{B C}\left(D_{p}, d_{p}\right) N\left(D_{p}\right) d D_{p}(\mathrm{~A} 1)$

where, $U\left(D_{p}\right)$ is the raindrop terminal velocity, $N\left(D_{p}\right)$ is the raindrop size distribution, and $E_{B C}\left(D_{p}, d_{p}\right)$ is the belowcloud collection efficiency, assumed equal with the collision efficiency (Slinn, 1983). The raindrop terminal velocity is taken as $U\left(D_{p}\right)=c \times D_{p}^{\gamma}$, with $\mathrm{c}=3.778$ and $\gamma=0.67$ (with $U$ in $\mathrm{ms}^{-1}$ and $D_{p}$ in $\mathrm{mm}$ ) (Atlas and Ulbrich, 1977). The raindrop size distribution is described by an empirical Marshall and Palmer (1948) fit, $N\left(D_{p}\right)=N_{0} \exp \left(-\Lambda D_{p}\right)$, where $N_{0}$ and $\Lambda$ depend on rainfall rate $R$ and can exhibit variability from case to case.

For UFP, the below-cloud collection efficiency is

$E_{B C}\left(D_{p}, d_{p}\right)=\frac{4}{R_{e} S_{c}}\left(1+0.4 R_{e}^{1 / 2} S_{c}^{1 / 3}+0.16 R_{e}^{1 / 2} S_{c}^{1 / 2}\right)+$

$4 \frac{d_{p}}{D_{p}}\left[\frac{\mu_{a}}{\mu_{w}}+\left(1+2 R_{e}^{1 / 2}\right) \frac{d_{p}}{D_{p}}\right]+E_{t}+E_{d}+E_{e}$

where the first six terms represent the Brownian diffusion and interception contributions to the collection efficiency (Slinn, 1977, 1983), and the last three terms represent the thermophoretic, diffusionphoretic and electric contributions (Davenport and Peters, 1978).
The thermophoresis contribution to collection efficiency is

$$
E_{t}=\frac{4 \alpha\left(2+0.6 R_{e}^{1 / 2} P_{r}^{1 / 3}\right)\left(T_{a}-T_{s}\right)}{U\left(D_{p}\right) D_{p}}
$$

where $\alpha=\frac{2 C_{c}\left(k_{a}+5 \frac{\lambda a}{D_{p}} k_{p}\right) k_{a}}{5 P\left(1+6 \frac{\lambda_{a}}{D_{p}}\right)\left(2 k_{a}+k_{p}+10 \frac{\lambda_{a}}{D_{p}} k_{p}\right)}$ and $P_{r}=\frac{c_{p} \mu_{a}}{k_{a}}$ is Prandtl number for air.

The diffusionphoresis effect on collection efficiency is

$E_{d}=\frac{4 \beta\left(2+0.6 R_{e}^{1 / 2} S_{c_{w}}^{1 / 3}\right)\left(\frac{p_{s}^{0}}{T_{s}}-\frac{p_{a}^{0} \mathrm{RH}}{T_{a}}\right)}{U\left(D_{p}\right) D_{p}}$

where $\beta=\frac{T_{a} D_{w}}{P}\left(\frac{M_{w}}{M_{a}}\right)^{1 / 2}$ and $S_{c_{w}}=\frac{\mu_{a}}{\rho_{a} D_{w}}$ is the Schmidt number for water vapor in air.

Other notations in the above equations are: $R_{e}=\frac{D_{p} U \rho_{a}}{2 \mu_{a}}$ is the raindrop Reynolds number, $S_{c}=\frac{\mu_{a}}{\rho_{a} D}$ is the aerosol Schmidt number, $\rho_{a}$ and $\mu_{a}$ are the air density and viscosity, $D=\frac{k_{B} T_{a} C_{c}}{3 \pi \mu_{a} d_{p}}$ is aerosol diffusivity in air, $k_{B}$ is the Boltzmann constant, $T_{a}$ is the air absolute temperature, $T_{S}$ is the absolute temperature of raindrop surface, $C_{c}$ is the Cunningham slip correction factor to account for non-continuum effects associated with small particles, $C_{c}=1+\frac{2 \lambda_{a}}{d_{p}}\left[1.257+0.4 \exp \left(-\frac{1.1 d_{p}}{2 \lambda_{a}}\right)\right]$, and $\lambda_{a}$ is the mean free path of air molecules. $k_{a}$ and $k_{p}$ are the thermal conductivity of air and aerosol particle, $D_{w}$ is the diffusivity of water vapor in air, $p_{a}^{0}, p_{s}^{0}$ are water vapor pressure at temperatures $T_{a}$ and $T_{s}, P$ is total air pressure, $M_{w}$ and $M_{a}$ are the molecular weight of water and air.

The term $E_{e}$ is based only on Coulomb interaction between charged aerosols and raindrops and is given by this expression $E_{e}=\frac{16 K C_{c} a^{2} \alpha^{2} d_{p}}{3 \pi \mu_{a} U}$, with $K=9 \times 10^{9} \mathrm{Nm}^{2} \mathrm{C}^{-2} \mathrm{~s}^{-1}$, 
$a=0.83 \times 10^{-6}, \alpha$ is an empirical parameter in the relations $Q=a \times \alpha D_{p}^{2}$, and $q=a \times \alpha d_{p}^{2}$ are the average charges on raindrop and aerosol particle (in $\mathrm{C}$ units). $\alpha$ can be varied between 0 , which corresponds to neutral particles, to $\sim 7$, which corresponds to highly electrified clouds, associated with thunderstorms (Pruppacher and Klett, 1998; Andronache, 2004).

The scavenging coefficient due to in-cloud collection by falling raindrops is

$L_{I C}^{\text {coll }}\left(d_{p}\right)=\int_{0}^{\infty} \frac{\pi}{4} D_{p}^{2} U\left(D_{p}\right) E_{I C} N\left(D_{p}\right) d D_{p}$

where $E_{I C}$ is the in-cloud collection efficiency between cloud droplets (of diameter $10 \mu \mathrm{m}$ ) and raindrops. $E_{I C}$ is in the range $0.5-0.8$ for soluble aerosol scavenged by liquid drops. For snow, the collection efficiency, $E_{I C} \sim 0.2-0.3$ (Scott, 1982).

The scavenging coefficient due to in-cloud coagulation between UFP and cloud droplets is

$L_{I C}^{\mathrm{coag}}\left(d_{p}\right)=\int_{0}^{\infty} \widetilde{K}\left(d_{c}, d_{p}\right) n_{c}\left(d_{c}\right) d d_{c}$

where $\widetilde{K}\left(d_{c}, d_{p}\right)$ is the Brownian coagulation kernel between UFP and cloud droplets, $d_{c}$ is the cloud droplet diameter. The coagulation kernel is based on Fuchs (1964). The cloud droplet size distribution is given by $n_{c}\left(d_{c}\right)=A d_{c}^{2} \times \exp \left(-B d_{c}\right)$, with $A=\frac{N_{c} B^{3}}{2}, B=\frac{3}{\bar{d}_{c}}$, where $\bar{d}_{c}$ is the average cloud droplet diameter, and $N_{c}$ is the total number concentration of cloud droplets (Pruppacher and Klett, 1998).

The calculations are carried out at aerosol particle diameter corrected by a growth factor $(G F)$, determined from observations as a function of particle diameter $d_{p}$ and ambient relative humidity RH. $G F$ is defined as $G F=\frac{d_{p}(\mathrm{RH})}{d_{p}\left(\mathrm{RH}_{0}\right)}$, where $d_{p}(\mathrm{RH})$ is the aerosol diameter at ambient relative humidity $\mathrm{RH}$ and $d_{p}\left(\mathrm{RH}_{0}\right)$ is the dry aerosol diameter as measured by the DMPS instrument at $\mathrm{RH} \leq 20 \%$. A fit of $G F$ that reproduces observations, valid for $\mathrm{RH} \leq 99 \%$, is given by:

$G F\left(\mathrm{RH}, d_{p}\right)=[1-\mathrm{RH} / 100]^{\varepsilon\left(d_{p}\right)}$

where $\varepsilon\left(d_{p}\right)=-3.11 \times 10^{5} \times \frac{d_{p}}{d_{p 0}}-0.0847$, and $d_{p 0}=1 \mathrm{~m}$. For $d_{p} \geq 280 \mathrm{~nm}, \varepsilon\left(d_{p}\right)=\varepsilon\left(d_{p}=280 \mathrm{~nm}\right)$ in this formulation (Laakso et al., 2004).

The parameterization of $L_{o}$ from observations is described by Laakso et al. (2003a):

$\log _{10}\left(L_{o} / L_{o}^{\prime}\right)=a+b \delta^{-4}+c \delta^{-3}+d \delta^{-2}+e \delta^{-1}+f\left(R / R_{0}\right)^{0.5}$

where: $\quad \delta=\log _{10}\left(d_{p} / d_{p 0}\right), \quad L_{o}^{\prime}=1 s^{-1}, \quad R_{0}=1 \mathrm{~mm} \mathrm{~h}^{-1}$, $d_{p 0}=1 \mathrm{~m}$. The coefficients $a, b, c, d, e, f$ are fitting parameters: $a=274.35758, b=332839.59273, c=226656.57259$, $d=58005.91340, e=6588.38582, f=0.244984$.

\section{Appendix B}

\section{Notations}

$d_{p} \quad$ ultrafine particles (UFP) diameter

$d_{c} \quad$ cloud droplet diameter

$D_{p} \quad$ raindrop diameter

E collection efficiency

$D \quad$ aerosol diffusivity in air

$D_{w} \quad$ water vapor diffusivity in air

$f_{1} \quad$ fraction of UFP mixed in-cloud

$f_{2} \quad$ in-cloud scavenged fraction of UFP

$G F \quad$ growth factor of UFP

$k_{a}, k_{p} \quad$ thermal conductivity of air, aerosol

$k_{B} \quad$ Boltzmann constant

$K\left(d_{c}, d_{p}\right) \quad$ Brownian coagulation kernel

$L_{\text {eff }} \quad$ effective scavenging coefficient

$L_{o} \quad$ scavenging coefficient from observations

$M_{a}, M_{w} \quad$ molecular weight of air, water

$n\left(d_{p}\right) \quad$ aerosol size distribution

$n_{c}\left(d_{c}\right) \quad$ cloud droplet size distribution

$N\left(D_{p}\right) \quad$ raindrop size distribution (RSD)

$N_{0} \quad$ Marshall and Palmer RSD parameter

$N_{0 g} \quad$ Gamma RSD parameter

$P \quad$ atmospheric pressure

$p_{a}^{0}, p_{s}^{0} \quad$ vapor pressure of water at temperature $T_{a}, T_{s}$

$P_{r} \quad$ Prandtl number for air

$R \quad$ rainfall rate near ground

$R_{I C} \quad$ rainfall rate in-cloud

RH relative humidity

$R_{e} \quad$ raindrop Reynolds number

$S_{c} \quad$ aerosol Schmidt number

$S_{c_{w}} \quad$ Schmidt number for water vapor in air

$U \quad$ raindrop terminal velocity

$t_{c} \quad$ air temperature in Celsius degrees

$T_{a} \quad$ absolute temperature of air

$T_{S} \quad$ absolute temperature of raindrop surface

$w_{b} \quad$ entrainment velocity at cloud base

$\lambda_{a} \quad$ mean free path of air molecules

$\mu_{a} \quad$ air viscosity

$\mu_{g} \quad$ Gamma RSD parameter

$\rho_{a}, \rho_{p} \quad$ density of air, aerosol

$\Lambda \quad$ Marshall and Palmer RSD parameter

$\Lambda_{g} \quad$ Gamma RSD parameter

Acknowledgements. The authors are grateful to M. Komppula for providing valuable information on cloud droplet activation process measurements and to S. Saku for synoptic weather data analysis. The authors thank the two referees for their critical comments and for their many helpful suggestions which improved the paper considerably.

Edited by: M. G. Lawrence 


\section{References}

Aalto, P., Hämeri, K., Becker, E., Weber, R., Salm, J., Mäkelä, J. M., Hoell, C., O’Dowd, C. D., Karlsson, H., Hansson, H.-C., Väkevä, M., Koponen, I. K., Buzorius, G., and Kulmala, M.: Physical characterization of aerosol particles during nucleation events, Tellus, 53B, 344-358, 2001.

Agusti-Panareda, A., Gray, S. L., and Methven, J.: Numerical modeling study of boundary-layer ventilation by a cold front over Europe, J. Geophys. Res., 110, D18304, doi:10.1029/2004JD005555, 2005.

Alam, A., Shi, J. P., and Harrison, R. M.: Observations of new particle formation in urban air, J. Geophys. Res., 108(D3), 4093, doi:10.1029/2001JD001417, 2003.

Allen, A. G., Grenfell, J. L., Harrison, R. M., James, J., and Evans, M. J.: Nanoparticle formation in marine air masses: Contrasting behavior of the open ocean and coastal environments, Atmos. Res., 51, 1-14, 1999.

Andreae, M. O. and Merlet, P.: Emission of trace gases and aerosols from biomass burning, Global Biogeochem. Cycles, 15, 955966, 2001.

Andronache, C.: Estimated variability of below-cloud aerosol removal by rainfall for observed aerosol size distributions, Atmos. Chem. Phys., 3, 131-143, 2003,

http://www.atmos-chem-phys.net/3/131/2003/.

Andronache, C.: Diffusion and electric charge contributions to below-cloud wet removal of atmospheric ultra-fine aerosol particles, J. Aerosol Sci., 35, 1467-1482, 2004.

Atlas, D. and Ulbrich, C. W.: Path and area integrated rainfall measurement by microwave attenuation in the $1-3 \mathrm{~cm}$ band, J. Appl. Meteorol., 16, 1322-1331, 1977.

Birmilli, W. and Wiedensohler, A.: New particle formation in the continental boundary layer: Meteorological and gas phase parameter influence, Geophys. Res. Lett., 27, 3325-3328, 2000.

Byrne, M. A. and Jennings, S. G.: Scavenging of sub-micrometer aerosol particles by water drops, Atmos. Environ., 27A, 14, 2099-2105, 1993.

Chate, D. M. and Pranesha, T. S.: Field studies of scavenging of aerosols by rain events, J. Aerosol Sci., 35, 695-706, 2004.

Covert, D. S., Kapustin, V. N., Quinn, P. K., and Bates, T. S.: New particle formation in the marine boundary layer, J. Geophys. Res., 97, 20 581-20 589, 1992.

Crutzen, P. J. and Lawrence, M. G.: The Impact of Precipitation Scavenging on the Transport of Trace Gases: A 3Dimensional Model Sensitivity Study, J. Atmos. Chem., 37, 1, doi:10.1023/A:1006322926426, 81-112, 2000.

Dana, M. T. and Hales, J. M.: Statistical aspects of the washout of polydisperse aerosols, Atmos. Environ., 10, 45-50, 1976.

Davenport, H. M. and Peters, L. K.: Field studies of atmospheric particulate concentration changes during precipitation, Atmos. Environ., 12, 997-1008, 1978.

Flossmann, A.: Interaction of aerosol particles and clouds, J. Atmos. Sci., 65, 879-887, 1998.

Fuchs, N. A.: The mechanics of aerosols, Pergamon Press Ltd, pp. 408, 1964.

Garrett, T. J. and Hobbs, P. V.: Long-range transport of continental aerosols over the Atlantic ocean and their effects on cloud structures, J. Atmos. Sci., 52, 2977-2984, 1995.

Greenfield, S.: Rain scavenging of radioactive particulate matter from the atmosphere, J. Meteorol., 14, 115-125, 1957.
Grover, S. N., Pruppacher, H. R., and Hamielec, A. E.: A numerical determination of the efficiency with which spherical aerosol particles collide with spherical water drops due to inertial impaction and phoretic and electric forces, J. Atmos. Sci., 34, 1655-1663, 1977.

Harrison, R. G. and Carslaw, K. S.: Ion-aerosol-cloud processes in the lower atmosphere, Rev. Geophys., 41(3), 1012, doi:10.1029/2002RG000114, 2003.

Harris, S. and Maricq, M.: Signature size distributions for diesel and gasoline engine exhaust particulate matter, J. Aerosol Sci., 32, 749-764, 2001.

Houze, R. A.: Cloud dynamics, Academic Press, pp. 573, 1993.

Hyvönen, S., Junninen, H., Laakso, L., Dal Maso, M., Grönholm, T., Bonn, B., Keronen, P., Aalto, P., Hiltunen, V., Pohja, T., Launiainen, S., Hari, P., Mannila, H., and Kulmala, M.: A look at aerosol formation using data mining techniques, Atmos. Chem. Phys., 5, 3345-3356, 2005, http://www.atmos-chem-phys.net/5/3345/2005/.

Jacobson, M. Z.: Analysis of aerosol interactions with numerical techniques for solving coagulation, nucleation, condensation, dissolution, and reversible chemistry among multiple size distributions, J. Geophys. Res., 107(D19), 4366, doi:10.1029/2001JD002044, 2002.

Jylhä, K.: Empirical scavenging coefficients of radioactive substances released from Chernobyl, Atmos. Environ., 25A, 263270, 1991.

Kerminen, V.-M. and Wexler, A. S.: The occurrence of sulfuric acid-water nucleation in plumes: Urban environment, Tellus, 48B, 65-82, 1996.

Komppula, M., Lihavainen, H., Kerminen, V., Kulmala, M., and Viisanen, Y.: Measurements of cloud droplet activation of aerosol particles at a clean subarctic background site, J. Geophys. Res., 110, D06204, doi:10.1029/2004JD005200, 2005.

Kulmala, M., Toivonen, A., Mäkelä, J. M., and Laaksonen, A.: Analysis of the growth of nucleation mode particles observed in Boreal forest, Tellus, 50B, 449-462, 1998.

Kulmala, M., Pirjola, L., and Mäkelä, M.: Stable sulfate clusters as sources of new atmospheric particles, Nature, 404, 66-69, 2000a.

Kulmala, M., Rannik, Ü., Pirjola, L., et al.: Characterization of atmospheric trace gas and aerosol concentrations at forest sites in southern and northern Finland using back trajectories, Boreal Env. Res., 5, 315-336, 2000 b.

Kulmala, M., Vehkamäki, H., Petäjä, T., Dal Maso, M., Lauri, A. Kerminen, V.-M., Birmili, W., and McMurry, P.: Formation and growth rates of ultrafine atmospheric particles: a review of observations, J. Aerosol Sci., 35, 143-176, 2004.

Laakso, L., Grönholm, T., Rannik, Ü., Kosmale, M., Fiedler, V., Vehkamäki, H., and Kulmala, M.: Ultrafine particle scavenging coefficients calculated from 6 years field measurements, Atmos. Environ., 37, 3605-3613, 2003a.

Laakso, L., Hussein, T., Aarnio, P., Komppula, M., Hiltunen, V., Viisanen, Y., and Kulmala, M.: Diurnal and annual characteristics of particle mass and number concentrations in urban, rural and Arctic environments in Finland, Atmos. Environ., 37, 26292641, 2003 b.

Laakso, L., Petäjä, T., Lehtinen, K. E. J., Kulmala, M., Patatero, J., Hörrak, U., Tammet, H., and Joutsensaari, J.: Ion production rate in a boreal forest based on ion, particle and radiation measurements, Atmos. Chem. Phys., 4, 1933-1943, 2004, 
http://www.atmos-chem-phys.net/4/1933/2004/.

Lawrence, G. M., von Kuhlmann, R., Salzmann, M., and Rasch, P. J.: The balance of effects of deep convective mixing on tropospheric ozone, Geophys. Res. Lett., 30, 18, 1940, doi:10.1029/2003GL017644, 2003.

Mäkelä, J. M., Dal Maso, M., Pirjola, L., Keronen, P., Laakso, L., Kulmala, M., and Laaksonen, A.: Characteristics of the atmospheric particle formation events observed at a boreal forest site in southern Finland, Boreal Env. Res., 5, 299-313, 2000.

Maria, S. S. and Russell, L. M.: Organic and Inorganic Aerosol Below-Cloud Scavenging by Suburban New Jersey Precipitation, Environ. Sci. Technol., 39(13) 4793-4800, 2005.

Marshall, J. S. and Palmer, W. M.: The distribution of raindrop with size, J. Meteorol., 5, 165-166, 1948.

Martin, G. M., Johnson, D. W., and Spice, A.: The measurement and parameterization of effective radius of droplets in warm stratocumulus clouds, J. Atmos. Sci., 51, 1823-1842, 1994.

Martinsson, B. G., Frank, G., Cederfelt, S. I., et al.: Droplet nucleation and growth in orographic clouds in relation to aerosol population, Atmos. Res., 50, 289-315, 1999.

McGann, B. T. and Jennings, S. G.: The efficiency with which drizzle and precipitation sized drops collide with aerosol particles, Atmos. Environ., 25A, 3/4, 791-799, 1991.

Niewiadomski, M.: A passive pollutant in a three-dimensional field of convective clouds: numerical simulations, Atmos. Environ., 20, 139-145, 1986.

O’Dowd, C., McFiggins, G., Creasey, D. J., Pirjola, L., Hoell, C., Smith, M. H., Allan, B. J., Plane, J. M. C., Heard, D. E., Lee, J. D., Pilling, M. J., and Kulmala, M.: On the photochemical production of new particles in the coastal boundary layer, Geophys. Res. Lett., 26, 1707-1710, 1999.

Pruppacher, H. R. and Klett, J. D.: Microphysics of clouds and precipitation, Kluwer Academic Publishers, Dordrecht, Boston, London, pp. 954, 1998.

Raes, F., van Dingenen, R., Cuevas, E., Van Velthoven, P. F. J., and Prospero, J. M.: Observations of aerosols in the free troposphere and marine boundary layer of the subtropical Northeast Atlantic: Discussion of processes determining their size distribution, J. Geophys. Res., 102, 21 315-21 328, 1997.

Rasch, P. J., Feichter, J., Law, K., et al.: A comparison of scavenging and deposition processes in global models: results from the WCRP Cambridge Workshop of 1995, Tellus, 52B, 1025-1056, 2000.

Rutledge, S. A. and Hobbs, P. V.: The mesoscale and microscale structure and organization of clouds and precipitation in midlatitude cyclones. VIII: A model for the feeder-seeder process in warm frontal rainbands, J. Atmos. Sci., 40, 1185-1206, 1983.

Schumann, T.: Aerosol and hydrometeor concentrations and their chemical composition during winter precipitation along mountain slope - III. Size-differentiated in-cloud scavenging efficiencies, Atmos. Environ., 25A, 3/4, 809-824, 1991.

Scott, B. C.: Theoretical estimates of the scavenging coefficient for soluble aerosol particles as a function of precipitation type, rate, and altitude, Atmos. Environ., 16, 7, 1753-1762, 1982.

Seinfeld, J. H. and Pandis, S. N.: Atmospheric Chemistry and Physics, Wiley, New York, 1326 pp., 1998.

Slinn, W. G. N. and Hales, J. M.: A reevaluation of the role of thermophoresis as a mechanism of in- and below-cloud scavenging, J. Atmos. Sci., 28, 1465-1471, 1971.
Slinn, W. G. N.: Some approximations for the wet and dry removal of particles and gases from the atmosphere, Water, Air, and Soil Pollut., 7, 513-543, 1977.

Slinn, W. G. N.: Precipitation scavenging, in: Atmospheric Sciences and Power Production - 1979, chap. 11, Division of Biomedical Environmental Research, U.S. Department of Energy, Washington, D.C., 1983.

Snider, J. R. and Brenguier, J. L.: Cloud condensation nuclei and cloud droplet measurements during ACE-2, Tellus B, 52, 828842, 2000.

Sparmacher, H., Fulber, K., and Bonka, H.: Below-cloud scavenging of aerosol particles: Particle-bound radionuclide - Experimental, Atmos. Environ., 27A, 4, 605-618, 1993.

Svenningsson, B., Hansson, H.-C., Martinsson, B., et al.: Cloud droplet nucleation scavenging in relation to the size and hygroscopic behavior of aerosol particles, Atmos. Environ., 31, 16, 2463-2475, 1997.

Swietlicki, E., Zhou, J., Berg, O. H., et al.: A closure study of submicrometer aerosol particle hygroscopic behavior, Atmos. Res., 50, 205-240, 1999.

Ten Brink, H. M., Schwartz, S. E., and Daum, P. H.: Efficient scavenging of aerosol sulfate by liquid-water clouds, Atmos. Environ., 21, 9, 2035-2052, 1987.

Tinsley, B. A., Rohrbaugh, R. P., Hei, M., and Beard, K. V.: Effects of image charges on scavenging of aerosol particles by cloud droplets and on droplet charging and possible ice nucleation processes, J. Atmos. Sci., 57, 2118-2134, 2000.

Tremblay, A.: Cumulus cloud transport, scavenging and chemistry: observations and simulations, Atmos. Environ., 21, 2345-2364, 1987.

Tripathi, S. N. and Harrison, R. G.: Scavenging of Radioactive Aerosol, Atmos. Environ., 35, 5817-5821, 2001.

Tost, H., Jöckel, P., Kerkweg, A., Sander, R., and Lelieveld, J.: Technical note: A new comprehensive SCAVenging submodel for global atmospheric chemistry modeling, Atmos. Chem. Phys., 6, 565-574, 2006, http://www.atmos-chem-phys.net/6/565/2006/.

Twohy, C. H., Durkee, P. A., Huebert, B. J., and Charlson, R. J.: Effects of aerosol particles on the microphysics of coastal stratiform clouds, J. Climate, 8, 773-783, 1995.

Vesala, T., Haataja, J., Aalto, P., Altimir, N., Buzorius, G., et al.: Long-term field measurements of atmosphere - surface interactions in boreal forest ecology, micrometeorology, aerosol physics and atmospheric chemistry. Trends in Heat, Mass and Momentum Transfer, 4, 17-35, 1998.

Wang, P. K. and Pruppacher, H. R.: An experimental determination of the efficiency with which aerosol particles are collected by water drops in subsaturated air, J. Atmos. Sci., 34, 1664-1669, 1977.

Wang, P. K., Grover, S. N., and Pruppacher, H. R.: On the effect of electric charges on the scavenging of aerosol particles by clouds and small raindrops, J. Atmos. Sci., 35, 1735-1743, 1978.

Weber, J. R., McMurry, P. H., Mauldin, L., et al.: A study of new particle formation and growth involving biogenic and trace gas species measured during ACE1, J. Geophys. Res., 103, 1638516396, 1998.

Wiedensohler, A., Covert, D. S., Swietlicki, E., Aalto, P., Heintzenberg, J., and Leck, C.: Occurrence of an ultrafine particle mode less than $20 \mathrm{~nm}$ in diameter in the marine boundary layer during 
Arctic summer and autumn, Tellus, 48B, 213-222, 1996.

Yu, F. and Turco, R.: From molecular clusters to nanoparticles: Role of ambient ionization in tropospheric aerosol formation, J. Geophys. Res., 106, 4797-4814, 2001.

Zhang, G., Vivekanandan, J., and Brandes, E.: A method for estimating rain rate and drop size distribution from polarimetric radar measurements, IEEE Transact. Geosci. Rem. Sens., 39, 830-841, 2001,
Zhang, L., Michelangeli, D. V., and Taylor, P. A.: Numerical studies of aerosol scavenging by low-level, warm stratiform clouds and precipitation, Atmos. Environ., 38, 4653-4665, 2004. 